\title{
BURROWING MITES THAT PESTER BIRDS
}

WILLIAM J. VAN SCHEIK, Canadian Union College, College Heights, Alberta. TOC OZO

The subzero winter temperatures of southern Alberta bring flocks of birds to fuel up on sunflowers seeds and suet at the feeder. As I watch them eating and bickering, I spot an Evening Grosbeak. It catches my attention because its legs and feet are heavily encrusted with scale, leaving them marginally functional. Closer inspection of this flock reveals more than $20 \%$ have some degree of scale. Though well known to poultry farmers and cage bird breeders, scaly-leg is seen only infrequently in wild birds. Scaly-leg is caused by one of the many species of mites that choose our feathered friends as hosts.

Mites, the smallest of arthropods (relatives of ticks and spiders), have a diversity equalled only by insects. These near-microscopic organisms have adapted to life on or in birds, insects and mammals, including man. Mange in dogs and scabies in man are manifestations of the presence of mites.

Most of the birds I observe are infested with mites. Some mites are so specific as to be found only on a single species of bird. One species of Rhinoecius is found only in the nasal passages of owls. Other species are restricted to single families of birds, such as Charadriiformes (shorebirds, gulls and auks). Several species of mites are endoparasitic and burrow under the skin or wander freely on or in air sacs, thoracic cavities, lungs or just about anywhere in the body cavity.
You may find mites in recently abandoned nests. Mites hiding in nesting material emerge to suck blood of incubating or brooding adults, or of hatchlings. Large numbers of nest mites on hatchlings can result in reduced growth rates, anaemia or even death. In some cases, adult birds have been sufficiently irritated by mites that incubation and brooding have been interrupted with resultant reproductive failure. The ubiquitous Northern Fowl Mite infests a large number of wild species and is an especially voracious blood feeder.

Check carefully among the feathers of birds you pick up. Feather mites live and feed on feathers and the horny layers of a bird's skin, but tend to avoid wing feathers. Apparently these mites have little effect on the host bird. Some species take up residence around the feather bases and burrow into the shafts. The resulting intense irritation may cause the host to pull feathers. This disrupts thermoregulation and may cause death due to hypothermia.

The scaly-leg on the Evening Grosbeak I saw is caused by the mite Cnemidocoptes mutant, indistinguishable from the scaly-leg mite familiar to poultry farmers. Although apparently the same species, there is no evidence that mites are spread between wild species and domestic flocks. A disease with essentially the same symptoms occurs in budgerigars and is caused by a closely related species, $C$. piloe. 


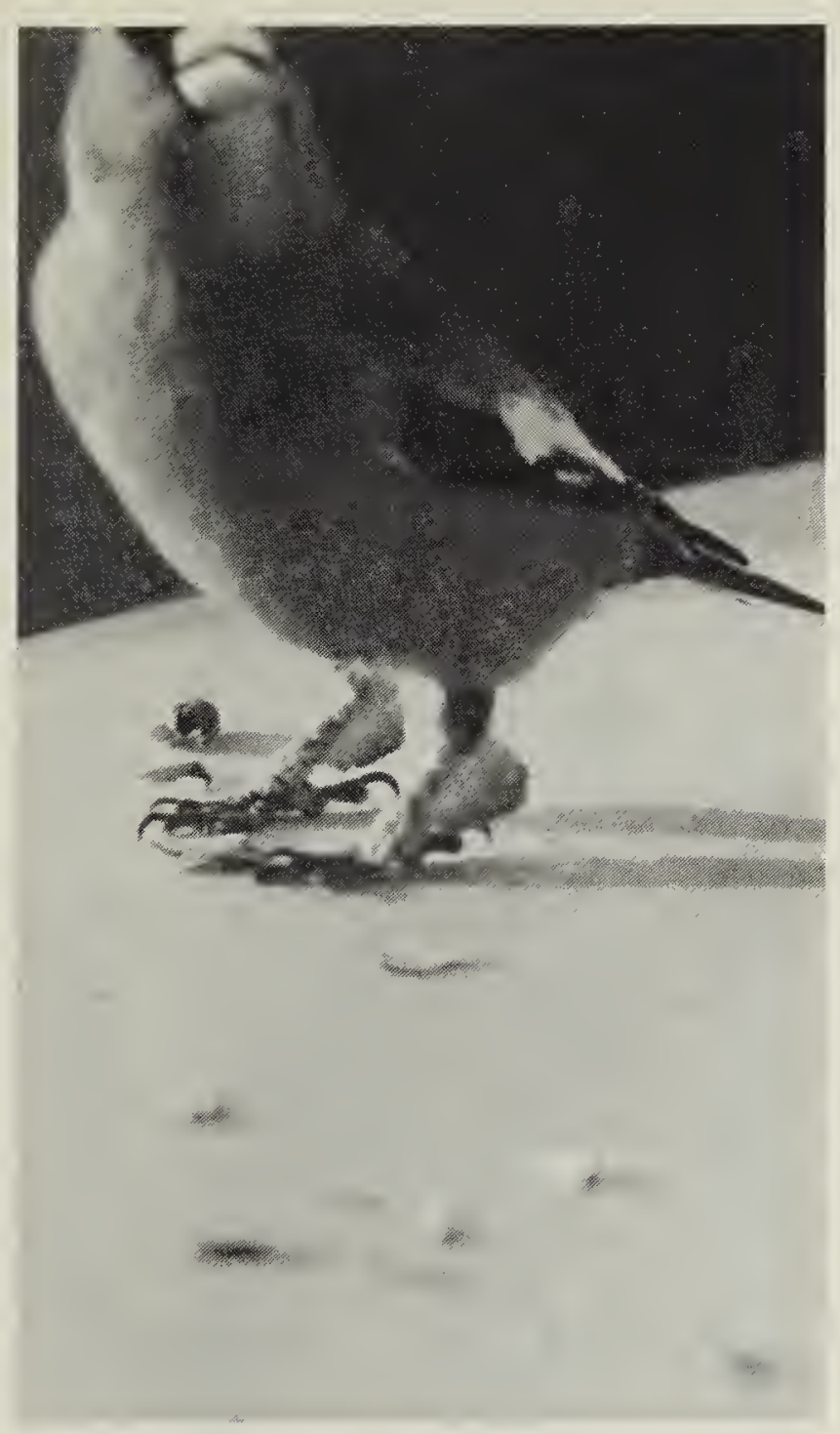

Evening Grosbeak with scaly-leg

H. Shultz

The first signs of infestation appear as a wart-like growth on the skin on the leg, cere or beak. In wild birds only the feet and legs are involved. Encrustations are caused by the burrowing of mites into the epithelial skin layers. Tissue proliferation is stimulated, resulting in scaling and hyperkeratosis (an overgrowth of tissue). Tunnels in the tissue contain adult mites and larvae. It seems likely that the parasite completes its life cycle on the host. Even in extremely heavy infestations, there is never evidence of inflammatory reaction.

Scaly-leg involves only the feet and legs. Birds with severe infestations may have shanks many times the normal diameter. Some birds I have observed have lost toes to the mites. In other birds, the disease has left the feet virtually dysfunctional, and such birds are seriously disadvantaged in foraging at feeding stations.

I carefully removed mites from a heavily infested male Evening Grosbeak. It's a good idea not to permit contact with the skin as mites are known to use humans as hosts. Female mites are spherical in shape, about $0.5 \mathrm{~mm}$ in diameter, with four short legs. Males are less than half that size but with longer legs. The head and thorax are fused together as in spiders and other arachnids.

Transmission between mature birds by contact has been difficult to demonstrate. The primary mode of transmission appears to be from parent to offspring during the nesting period. Direct contact, allowing infection, occurs during brooding and feeding of nestlings. Perhaps infected members of a flock are closely related.

The relatively large amount of time birds spend in maintenance activity may be necessary to keep mite populations in check. Preening, dust and water baths likely reduce the number of resident parasites. Anting (rubbing ants among the feathers) has been observed in 150 species of birds. Ornithologists believe that the formic acid produced by the ants may be used by birds as a mite repellent.

Scaly-leg, though not common in wild species, has been reported in House Sparrows, Cassin's Finches, Evening Grosbeaks, White-breasted Nuthatches, Red-winged Blackbirds, Common Grackles, Brown-headed Cowbirds, Black-capped Chickadees, and Crested Flycatchers. Watch for evidence of mites when you go bird watching. You might find new names to add to the list of infected species. 